\title{
Discussion: Prospects in elongation of railway transition curves
}

Piotr Chrostowski PhD

Assistant Professor, Department of Rail Transportation and Bridges Structures, Faculty of Civil and Environmental Engineering, Gdansk University of Technology, Gdansk, Poland (corresponding author: piochros@pg.edu.pl, piotrchrost@gmail.com) (Orcid:0000-0002-5454-026X)

\section{Wladyslaw Koc DSc, PhD}

Professor, Department of Rail Transportation and Bridges Structures, Faculty of Civil and Environmental Engineering, Gdansk University of Technology, Gdansk, Poland (Orcid:0000-0002-4619-7852)

\section{Katarzyna Palikowska PhD}

Assistant Professor, Department of Rail Transportation and Bridges Structures, Faculty of Civil and Environmental Engineering, Gdansk University of Technology, Gdansk, Poland

Sakdirat Kaewunruen BEng (Hons), MEng, PhD, MBA, MIEAust, CPEng, NER, RPEQ, FHEA, APEC Eng

Senior Lecturer, Birmingham Centre for Railway Research and Education,

The University of Birmingham, Birmingham, UK

(Orcid:0000-0003-2153-3538)

\section{Contribution by Sakdirat Kaewunruen}

The paper under discussion (Chrostowski et al., 2017) presents an elongation of existing transition curves during track renewal to improve allowable train speed and ride comfort. Horizontal arcs or alignments have been re-designed to enable longer and smoother track cant transition (or superelevation transition). This will effectively reduce track twist during the transition. However, it should be further noted that the consideration should also embrace a system thinking approach, whether it is a semi-green or brownfield project. Life-cycle evaluation should be a key concern for track designers as to whether the transition elongation is suitable (Kaewunruen et al., 2015). Mostly, transition curves adopt a cubic parabola formulation to estimate coordinates along the joining transition arc length between the transition point and a curve arc. In practice, it is very difficult to align rail cant to match the transition requirements perfectly. This aspect is crucial for life-cycle management and maintenance of railway tracks. Very frequently, rail surface defects are found along the transition arc length, as shown in Figure 11 (Kaewunruen and Ishida, 2015; Wilson et al., 2012). The rail replacement in this section thus becomes very costly, as the whole length or majority of the rail length must be re-railed for dimensional and functional compatibility. On this ground, unless the wheel-rail condition is properly managed, the elongation of such a transition arc length could potentially lead to higher costs and time for either planned or unplanned track maintenance.

\section{Authors' reply}

The authors would like to thank Dr Kaewunruen for his interesting comments. Certainly, the problem of track maintenance is crucial and the relation between track geometry and wheel-rail interface problems becomes very important. The authors agree that there is a correlation between rail surface failures and the wheel-rail contact forces, which relates to the curvature distribution. However, unmatched non-linear sections are still a problem from the point of view of train

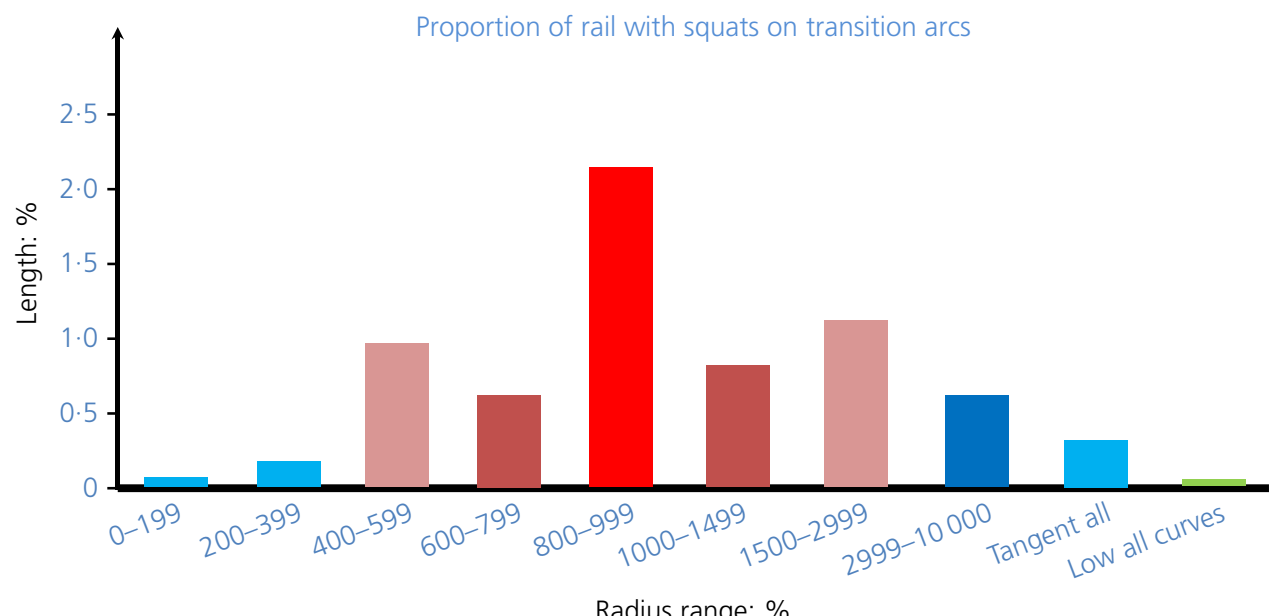

Figure 11. Distribution of rail surface defects on transition curves (adopted from Wilson et al. (2012)). A full-colour version of this figure can be found on the ICE Virtual Library (www.icevirtuallibrary.com) 
Transport

Volume 174 Issue 4
Discussion: Prospects in elongation of

railway transition curves

Chrostowski, Koc, Palikowska and

Kaewunruen operation, railway capacity and so on. Investigations carried out by Dr Kaewunruen could increase the value of railway geometric layout optimisation by providing the additional criteria. This issue - the relation between geometric parameters and mechanical ones - is surely important in the area under investigation. A railway superstructure's reliability and durability are the outcome of various factors, and a final optimisation process could comprise a large number of criteria, including also pointed rolling contact fatigue problems. The authors believe that their geometric analysis adds measurable benefits for the general theory of railway planning and design (and practice also) which supports railway engineers.

\section{REFERENCES}

Chrostowski P, Koc W and Palikowska K (2017) Prospects in elongation of railway transition curves. Proceedings of the Institution of Civil Engineers - Transport, https://doi.org/10.1680/jtran.17.00097.

Kaewunruen S and Ishida M (2015) In situ monitoring of rail squats in three dimensions using ultrasonic technique. Experimental Techniques 40(4): 1179-1185, https://doi.org/10.1111/ext.12171.

Kaewunruen S, Ishida M and Marich S (2015) Dynamic wheel-rail interaction over rail squat defects. Acoustics Australia 43(1): 97-107.

Wilson A, Kerr MB, Marich S and Kaewunruen S (2012) Wheel/rail conditions and squat development on moderately curved tracks. Proceedings of Conference of Railway Engineering, Brisbane, Australia. 